\title{
Aplicações de realidade aumentada no ensino de Física a partir do software LAYAR
}

Luciano Denardin de Oliveira - Facul. Física (PUCRS) - luciano.denardin@ pucrs.br Ramón Cid Manzano - Depto Didácticas Aplicadas (USC) - ramon.cid@usc.es

\section{Resumo}

Neste trabalho exploramos alguns aspectos e características da realidade aumentada e apresentamos uma outra forma de trabalho com essa tecnologia pouco empregada na área educacional a partir do software LAYAR. Explicamos o funcionamento do software e de suas principais ferramentas, sugerindo como que cada uma delas pode ser usada em aulas de física. Um exemplo de material didático incrementado com recursos de realidade aumentada empregando o LAYAR também é detalhado. Por fim, acreditamos que essa tecnologia se aproxima muito das características que atendem às demandas educacionais atuais e se revela uma versátil ferramenta para contribuir na qualificação da prática docente.

Palavras-chave: Realidade aumentada, LAYAR, ensino de física.

\section{Application of augmented reality in physics teaching from LAYAR software}

\begin{abstract}
This paper is about some aspects and some features of augmented reality which are explored in a different way. To do so, it is described another kind of task through LAYAR software which is not often used in education. First of all, it is given the operation of the software and after its main tools. Also, there are the usages of each tool in physics classes as a suggestion. It is also included as an example an enriched courseware with augmented reality resources which LAYAR is used and detailed. Thus, it is believed that this technology approaches the features which follow the present demands of education and it reveals a versatile tool to contribute the qualification of teaching practice.
\end{abstract}

Keywords: Augmented Reality, LAYAR, physics education.

\section{Introdução}

Os alunos dos dias de hoje nasceram e se desenvolvem imersos na tecnologia digital, tendo uma habilidade inata no uso de computadores, tablets, smartphones e internet, sendo conhecidos como nativos digitais. Em contrapartida, muitos de seus professores, denominados imigrantes digitais, tiveram que incorporar essas tecnologias ao longo da vida (PRENSKY, 2001). Os (alunos) nativos digitais raciocinam de forma diferente, são mais imediatistas, realizam várias tarefas de maneira simultânea e coletivamente. Acessam informações aleatória, superficial e concomitantemente, preferindo imagens e vídeos em detrimento a textos (ibid). Entretanto, tem uma tendência a mudarem de atividade rapidamente, o que pode acarretar na perda de produtividade, indicando uma dificuldade de concentração e um tempo muito pequeno de atenção em uma determinada tarefa (GARCÍA et al, 2007). Muitos dos (professores) imigrantes 
digitais, acreditam no mesmo modelo de ensino no qual foram educados, em um ensino lento e sequencial, pautado na repetição. A aprendizagem é linear, o conteúdo deve ser memorizado de forma que todo o processo está centrado nas atitudes do professor (PRENSKY, 2001; GARCÍA et al, 2007). Este descompasso pode ser um fator conflitante na forma do professor ensinar e do aluno aprender e talvez seja uma das justificativas do desinteresse e insatisfação dos estudantes pelas questões acadêmicas.

Neste sentido o modelo atual de ensino não tem se mostrado adequado aos estudantes, de forma que não apenas os conteúdos a serem ensinados devem mudar, mas também a maneira pelas quais são abordados, socializados e discutidos. Por essa dinamicidade do nativo digital, o professor deve diversificar as atividades propostas, desenvolvendo um pluralismo metodológico em sala de aula (LABURÚ, ARRUDA e NARDI, 2003), bem como fazer uso das novas tecnologias para favorecer o aprendizado.

Uma das possibilidades de aproximar as propostas pedagógicas dos interesses dos alunos é por meio de atividades envolvendo realidade aumentada. Para contribuir com essa iniciativa, apresentamos o software LAYAR que é de fácil utilização e pode tanto ser utilizado por nativos quanto imigrantes digitais.

\section{Realidade Aumentada}

A expressão realidade aumentada (RA) foi cunhada por Caudell e Mizell em 1992, e pode ser definida como a incorporação de objetos virtuais em um ambiente real por meio de um dispositivo tecnológico, incrementando e aumentando a visão que o usuário tem do mundo real (KIRNER e KIRNER, 2007; FORTE e KIRNER, 2009). Segundo Azuma (1997), a RA é estabelecida quando existe uma sobreposição em tempo real de objetos virtuais tridimensionais em ambientes reais. Neste sentido a RA diferencia-se da realidade virtual (RV). Na RV todo ambiente é virtual e o usuário interage também com objetos virtuais para que tenha capacidade de perceber esse ambiente. Na RA o usuário mantém seu senso de presença no ambiente real, interagindo apenas com objetos virtuais que ampliam suas sensações e percepções (FORTE e KIRNER, 2009). Diferentemente da RV, na RA não há uma imersão total na virtualidade, de forma que elementos virtuais devem parecer integrados ao ambiente real, incrementando a percepção do usuário.

Para a produção de um ambiente de RA utiliza-se geralmente marcadores fiduciais (pequenos cartões de papel nos quais códigos específicos são impressos). Um objeto virtual (geralmente tridimensional) produzido no computador é associado ao respectivo marcador por meio de bibliotecas e softwares específicos de RA como o ARToolKit, o FLARTOOLKIT e o FLARAS. Ao direcionar este marcador para uma câmera, essa capta a imagem e a transmite para o software de RA. Em tempo real, o software identifica o objeto virtual que está associado ao respectivo marcador, posicionando-o corretamente sobre ele e renderizando-o ${ }^{1}$. Ao observar a tela do computador, enxerga-se o cenário real com a sobreposição do elemento virtual sobre o marcador. O movimento tanto de translação quanto de rotação do marcador permite visualizar outras regiões do elemento virtual tridimensional. Todavia, a RA não exige, obrigatoriamente, o uso de marcadores fiduciais para a incorporação de elementos virtuais em um ambiente real. É possível adicionar os objetos virtuais a partir de informações de locais obtidas via global positioning system (GPS) ou softwares que identificam o cenário real por suas texturas,

\footnotetext{
${ }^{1}$ Renderizar pode ser entendido como o ato de gerar um produto final a partir de um processamento digital.
} 
linhas, geometrias e pontos (TEICHRIEB, 2007 apud SOUSA, 2015 p. 56).

Muitos softwares de RA e bibliotecas de objetos tridimensionais são gratuitos, bem como, o recurso necessário para seu uso limita-se a um computador munido de uma câmera (que pode ser a própria webcam), sinalizando que o custo para sua implementação e utilização é mínimo quando comparado à RV, por exemplo.

A RA proporciona novas formas de interação humano-computador, auxiliando na manipulação de dados. Ela se mostra multissensorial e aumenta a percepção do usuário no uso de uma interface computacional (ROLIM et al, 2011). No caso do ensino, a RA pode apresentar uma série de vantagens, entre as quais destaca-se a suave transição entre realidade e virtualidade. Além disso, no momento em que um material didático é incrementado com elementos virtuais amplia-se os aspectos sensoriais desse material, podendo aumentar a capacidade cognitiva de aprendizagem (ROLIM et al, 2011). Por se mostrar amplamente interativa o uso dessa tecnologia pode estimular e motivar os estudantes nas questões acadêmicas. Além disso, as atividades propostas envolvendo RA podem ser realizadas pelo aluno também fora do ambiente escolar e no seu próprio ritmo. A RA é de baixo custo e não exige que os alunos estejam familiarizados com essa tecnologia, pois é de simples utilização.

Outra vantagem é que o uso desses recursos na discussão de um tema abstrato ou distante da realidade do aluno pode potencializar a compreensão, incorporando detalhes, simulando movimentos e dinamizando situações (FORTE e KIRNER, 2009; CARDOSO et al 2014). Assim, a incorporação de elementos tridimensionais ou até mesmo o uso de fotografias, sons e vídeos possibilitam ao aluno uma visão mais ampla do que está sendo discutido, tornando o tema mais contextualizado e menos abstrato (FORTE e KIRNER, 2009). Ademais, a sobreposição de elementos virtuais em experimentos reais pode favorecer a investigação do modelo científico proposto e auxiliar na compreensão do fenômeno físico envolvido (SOUSA, 2015). Segundo Viegas et al (2012) a RA permite que os usuários tenham um controle sobre o sistema e possibilita que os objetos virtuais reproduzam as leis da física. Além disso, a RA pode contribuir com o aprendizado por inserir objetos virtuais tridimensionais, como de fato é a natureza (e não bidimensionais como mostrado em um quadro-negro de sala de aula ou em um livro didático). Permite ainda a simulação de situações físicas reais que são difíceis ou inviáveis de serem reproduzidas no ambiente escolar, como a manipulação de elementos como planetas, estrelas e satélites, ou atividades envolvendo radioatividade e substâncias nocivas.

No Ensino de Física diversos trabalhos já foram realizados utilizando RA. Viegas et al (2012), relatam no seu artigo o desenvolvimento de materiais de apoio envolvendo RA. Apresentam simulações de colisões elásticas, lançamentos verticais, planos inclinados e pêndulos simples.

Camargo et al (2010) elaboraram um livro didático de física para o ensino médio assistido por RA. O material possui as unidades didáticas usuais trabalhadas em sala de aula e apresentam, além da teoria, marcadores que permitem a utilização de RA pelos alunos. Em uma avaliação via questionário utilizando escala Likert e respondido por professores e alunos que interagiram com o material, os autores constataram que a aceitabilidade da RA foi significativa, bem como de fácil utilização e interessante.

Souza e Kirner (2011) desenvolveram um conteúdo de RA para ser utilizado em conjunto com um experimento real. Utilizando marcadores fiduciais é possível identificar o sentido real da corrente elétrica e as linhas de campo magnético produzidas pela corrente elétrica no fio condutor. Permite ainda inverter o sentido da corrente elétrica, abrir e fechar o circuito e reproduzir o experimento de Oersted. Na mesma linha, Sousa (2015), utilizando um circuito elétrico real simples, incorpora elementos virtuais para a compreensão do modelo de Drude para a condução elétrica em metais. 
Como podemos observar os trabalhos apresentados acima envolvem a incorporação de elementos tridimensionais via softwares de RA, ora em experimentos reais, ora em materiais didáticos. Neste trabalho apresentamos uma variação da RA. Os elementos virtuais a serem incorporados via RA não serão objetos tridimensionais, mas sim imagens, sons, vídeos, páginas na internet, etc. Neste sentido, apresentamos uma maneira alternativa de fornecer informações adicionais ao estudante a partir da RA e que não faz uso de marcadores fiduciais. Para tanto, utiliza-se um software específico de RA que possui tais características, a saber, o LAYAR.

\section{O Software LAYAR}

O LAYAR é um software para criação e editoração de conteúdos de RA, destinado majoritariamente às áreas de publicidade, arquitetura e turismo, sendo muito incipiente seu uso no ensino. A empresa foi criada em 2009 e contava, em janeiro de 2016, com mais de 500000 páginas com conteúdo de RA publicadas e com o aplicativo instalado em mais de 40 milhões de dispositivos. Por meio de um aplicativo ${ }^{2}$ homônimo gratuito instalado em dispositivos móveis ${ }^{3}$, é possível acessar os conteúdos de RA previamente preparados. Ele permite o acesso a informações digitais sobrepostas a materiais impressos ou ambientes reais por meio da câmera do dispositivo e seus "marcadores" podem ser o próprio material impresso ou um local real, pois também utiliza o GPS para identificação.

Mediante um cadastro gratuito na página da internet da empresa (www.layar.com) o usuário pode começar a incorporar elementos de RA nos materiais que desejar. $\mathrm{O}$ software denomina de campanha (campaign) cada material no qual será incluído conteúdos de RA. Ao iniciar uma nova campanha o usuário deve selecionar um arquivo nos formatos .jpg, .png, .pdf ou .zip previamente editado e nos quais os conteúdos de RA serão sobrepostos. Após o upload do arquivo, é possível iniciar o processo de editoração e inclusão dos elementos de RA. Os objetos podem ser adicionados em algumas ou em todas as páginas do material importado pelo editor e que constitui a campanha.

A editoração é simples de ser realizada e o software é muito intuitivo. As principais funções do LAYAR associadas aos elementos de RA que podem ser incluídas, bem como sugestões de objetos associados ao ensino de física estão descritas abaixo:

a) OPEN A WEBSITE: Este botão direciona para um site previamente definido. O botão pode ser uma imagem escolhida pelo editor ou ter a aparência padrão do software (com opções de diversas cores). É possível ainda incluir um título ao botão e animá-lo.

Com este recurso o professor pode fazer com que o aluno seja direcionado rapidamente para um site de interesse, dispensando que o estudante tenha que digitar o respectivo $U R L$ no navegador. É possível associar a esse recurso links para simulações computacionais como o PhET interactive simulations (PHET, 2015). O aluno também pode ser direcionado para sites que contenham material de apoio à aprendizagem, reportagens e artigos pertinentes. Uma possibilidade é o professor customizar o botão com a imagem de cientistas envolvidos com a temática proposta e, ao clicar no botão, o aluno é direcionado para uma página da internet que contenha sua biografia, por exemplo.

b) SHOW AN IMAGE: Esta opção exibe uma imagem pré-estabelecida apresentando-a isoladamente. Por uma questão de custo, os materiais entregues aos alunos nas escolas brasileiras geralmente são impressos em preto e branco. Com o uso

\footnotetext{
${ }^{2} \mathrm{O}$ aplicativo para smartphones e tablets pode ser obtido em: https://www.layar.com/mobile

${ }^{3}$ Neste texto o termo dispositivo móvel deve ser entendido como smartphones e tablets.
} 
desse conteúdo de RA o aluno pode visualizar imagens coloridas o que pode ser de grande valia, por exemplo, no estudo da luz e na decomposição das cores. É possível ainda vincular este recurso com gráficos ou tabelas do tema discutido.

c) SHOW A CAROUSEL: Nesta opção uma sequência de até 12 imagens é exibida, uma a uma. Este recurso é mais versátil que o anterior e o próprio usuário passa de uma imagem para a outra. Como exemplos no ensino de física, o professor pode incluir imagens das configurações das linhas de campo magnéticas e/ou elétricas. As imagens podem ainda ser exemplos de situações do cotidiano que ilustrem as leis de Newton ou de dispositivos elétricos como resistores, capacitores, etc. Por uma questão de redução nos custos de impressão, o professor pode disponibilizar algumas imagens que tradicionalmente estariam impressas, na forma de conteúdo em RA e reduzir o número de páginas do material. É possível preparar uma sequência de imagens nas quais a primeira seja um questionamento sobre determinado tópico e a subsequente, a resposta. Por exemplo, o professor adiciona imagens de fenômenos ondulatórios (reflexão, refração, difração, interferência, polarização, etc.) solicitando que o aluno os identifique. O aluno reflete sobre o perguntado e depois verifica a resposta correta. É possível também que essa sequência de imagens sejam passos de uma atividade de investigação.

Uma proposta interdisciplinar interessante e que pode ser explorada por meio desse recurso é a discussão entre física e arte. O professor pode abordar questões envolvendo obras de artistas consagrados e associá-las com a física, como sugerido por: Andrade, Nascimento e Germano (2007) e Gomes, Di Giorgi e Raboni (2011).

d) PLAY VIDEO: Este botão executa um vídeo previamente definido pelo editor. O LAYAR suporta links do youtube e arquivos na extensão .mp4. Com este recurso podese incluir um documentário ou reportagem que gostaria que o aluno assistisse, como por exemplo a recente detecção das ondas gravitacionais ou do bóson de Higgs. Pode-se trabalhar vídeos históricos relacionados com a segunda guerra mundial, visando discutir a bomba atômica e a fissão nuclear. Uma outra sugestão seria explorar alguma situação do cotidiano que remeta a um fenômeno físico, como a decomposição de vetores em aviões em pouso com vento de través ou vídeos que ilustrem o funcionamento de motores e ciclos termodinâmicos. Pode-se ainda utilizar vídeos de aviões viajando acima da velocidade do som ou ainda movimentos de carrinhos de montanhas-russas em parques de diversões e/ou saltos de bungee jump objetivando estimar valores envolvendo energias cinética, potencial e mecânica e sua dissipação. É possível ainda utilizar vídeos de demonstrações experimentais que não possam ser reproduzidas na escola por falta de recursos disponíveis ou outra razão. Exemplos seriam as exibições de diversos vídeos disponíveis envolvendo bobinas de Tesla e gaiolas de Faraday e que ilustram de forma muito impactante a blindagem eletrostática, ou ainda experimentos acerca do ponto triplo d'água e a superfusão. O professor pode incluir ainda cenas de filmes e/ou comerciais e analisá-los fisicamente como sugeridos nos trabalhos de Souza e Moreira (2005), Oliveira (2006), Silveira (2011) e Piassi (2013).

e) PLAY AUDIO: É possível incluir áudios ao material preparado. Este áudio pode ser executado imediatamente após a varredura do aplicativo instalado no dispositivo móvel ou a bel-prazer do usuário.

Nas aulas de física esse recurso pode ser utilizado em várias dimensões. É possível empregá-lo no estudo da acústica incluindo exemplos de sons graves e agudos, bem como explorar conceitos como batimento e timbre. Para esse, sugere-se o uso de um aplicativo de dispositivo móvel que opere como frequencímetro, permitindo que os alunos constatem que a frequência emitida por diferentes instrumentos é a mesma. Além disso, pode-se explorar conceitos científicos a partir de letras de música como sugerido por Moreira e Massarani (2006). 
f) VOTE IN A POLL: Esta opção permite que o editor adicione uma enquete com quatro alternativas. As respostas dadas pelos usuários são disponibilizadas, de forma percentual, nas estatísticas da respectiva campanha. O professor pode elaborar alguns testes de múltipla escolha para funcionarem como avaliador prévio dos conhecimentos dos alunos ou a serem respondidos por eles durante ou ao final da atividade proposta. $\mathrm{O}$ professor pode acompanhar em tempo real as respostas dos alunos e discutir aqueles temas que mais apresentaram respostas incorretas, bem como redirecionar o curso da aula baseado nessas respostas.

g) DOWNLOAD A MOBILE APP: Permite indicar aplicativos para serem instalados nos dispositivos móveis dos usuários. Existe uma infinidade de aplicativos que podem ser empregados no ensino de física. Dependendo da área que o professor estiver trabalhando, pode sugerir para os alunos instalarem em seus dispositivos móveis desde conversores de unidades e bússolas, passando por decibelímetros, frequencímetros e espectrômetros e chegando na análise de dados reais do LHC (grande colisor de hádrons) - o acelerador de partículas do CERN. Alguns jogos envolvendo reflexão da luz e construção de pontes também podem ser explorados.

h) LIKE YOUR PAGE ON FACEBOOK: O usuário pode ser encaminhado a uma determinada página na rede social facebook. Caso o professor tenha alguma fanpage na rede social citada e julgar pertinente direcionar os alunos para ela, esse recurso facilita o processo. Talvez essa (e o próximo item) sejam meios de permitir a socialização das atividades realizadas entre os alunos.

i) SHARE A MESSAGE ON TWITTER: Permite que o usuário compartilhe uma mensagem na rede social twitter e pode ser útil caso o professor almeje realizar alguma atividade envolvendo esta rede social.

j) SEND YOU AN EMAIL: O usuário pode enviar um email para um endereço previamente cadastrado pelo editor. Dependendo do tipo de atividade o professor pode solicitar que algumas respostas do material preparado sejam encaminhadas ao email presente no material.

Acima apresentamos as principais funções do software de RA LAYAR. Após finalizado o processo de editoração o professor pode testar e posteriormente publicar o material com conteúdo de RA.

No caso do ensino, o professor pode preparar um material de aula em um editor de texto padrão e salvá-lo no formado pdf. Por meio do software LAYAR, incorpora os elementos de RA que desejar e publica a campanha. Em aula, o professor disponibiliza o material impresso para os estudantes e com o auxílio de um dispositivo móvel com o aplicativo LAYAR previamente instalado os alunos fazem a varredura desse material. $\mathrm{O}$ aplicativo interpreta o material como um marcador de RA e mostra na tela do dispositivo móvel, sobreposto ao material impresso, todo o conteúdo de RA que o professor havia preparado anteriormente. A partir desse momento os alunos interagem com os elementos virtuais da forma e no momento que desejarem. Alertamos que o aplicativo só funciona com dispositivos móveis conectados à internet.

\section{Um exemplo de um material didático com conteúdo de RA}

A seguir apresentamos um exemplo de material didático contendo elementos de RA utilizado por um dos autores ao ministrar um minicurso sobre RA no VI Encontro Estadual de Ensino de Física. Por conta dos participantes do minicurso serem professores da educação básica, licenciandos em Física e alunos de pós-graduação, o conteúdo de RA foi pensado para esse público, mas também tentamos aproximar ao máximo de um material que tivesse potencial para ser empregado no ensino médio. 
A figura 1A apresenta o material disponibilizado de forma impressa aos participantes do minicurso e envolve um problema acerca do conceito de empuxo. A atividade proposta está inspirada no artigo de Oliveira (2012) e parte de uma imagem que faz alusão a uma cena do filme Titanic e que foi amplamente difundida nas redes sociais na ocasião do relançamento do filme em uma versão 3D. A imagem mostra o casal protagonista do filme nas águas gélidas do oceano Atlântico após o naufrágio da embarcação e sugere que haveria espaço sobre um fragmento de madeira para ambos (e não apenas para a atriz), de forma que a morte de um dos personagens poderia ter sido evitada. $\mathrm{O}$ autor do artigo parte dessa situação para avaliar as condições de flutuabilidade do fragmento de madeira para as situações nas quais encontram-se sobre ele: apenas a atriz; o casal. Conclui que o fragmento de madeira fica parcialmente submerso quando apenas a atriz está sobre ele, mas que o mesmo não aconteceria quando o ator também estivesse sobre a madeira. Além disso, o autor sugere diversos desdobramentos e questões que podem ser exploradas a partir da situação explicitada.
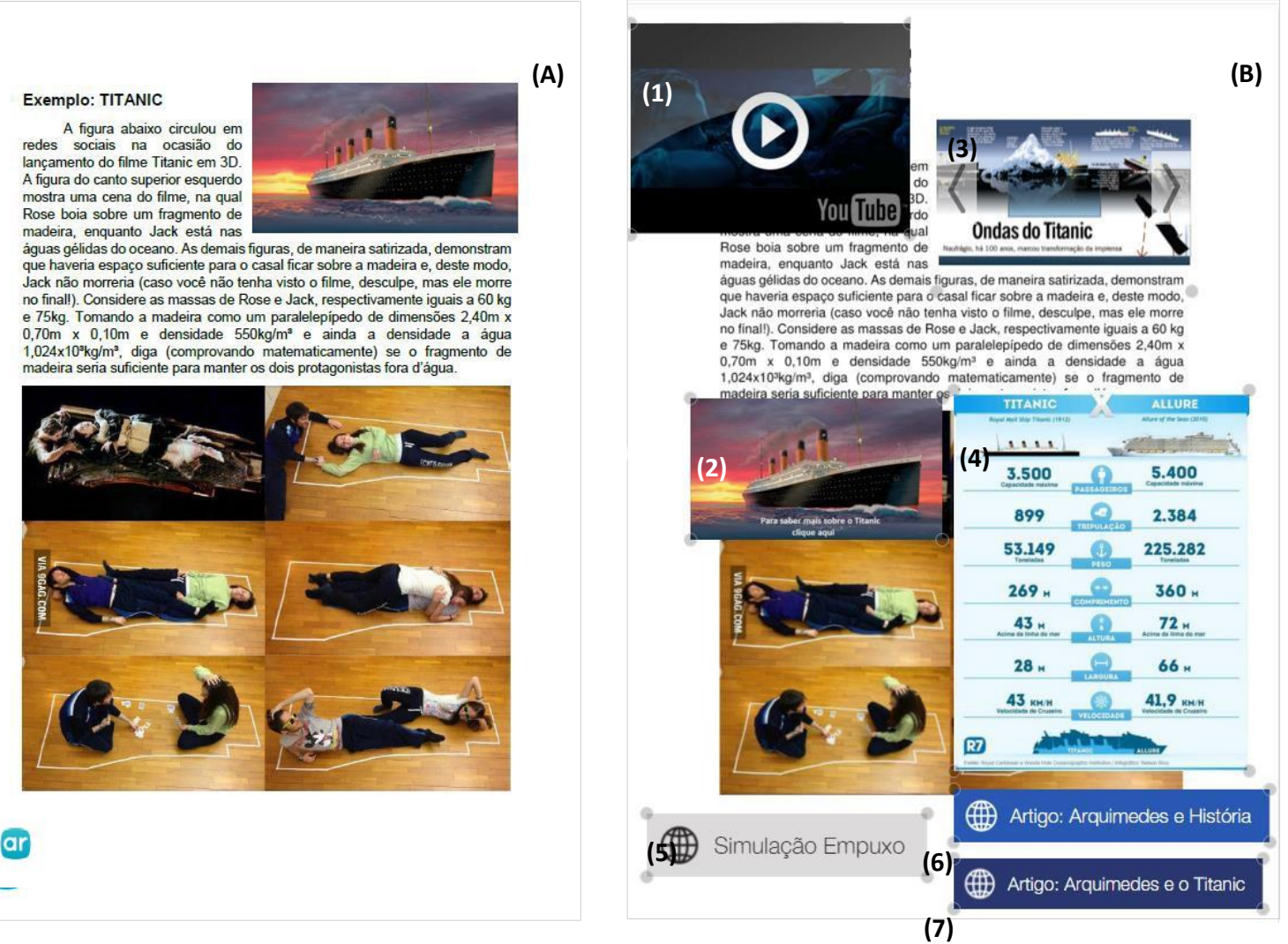

Figura 1 - (A) Material preparado previamente pelo professor. (B) Objetos de Realidade Aumentada (1-7) observados quando o aluno faz a varredura do material (A) com o aplicativo LAYAR via dispositivo móvel.

Partindo desse contexto, o material mostrado na figura 1A questiona se o fragmento de madeira seria suficiente para manter os dois protagonistas fora d'água. Neste material apresentado na figura 1A incluiu-se no canto inferior esquerdo um logotipo do aplicativo LAYAR. Esta é uma forma de indicar ao usuário que aquele material em especial possui conteúdo em RA alertando-o para realizar o escaneamento via aplicativo do dispositivo móvel nesta respectiva página.

A figura 1B apresenta $\mathrm{o}$ aspecto do mesmo material após realizado o escaneamento pelo LAYAR. Observa-se que 7 elementos são incorporados, de forma a 
ampliar os recursos disponibilizados, caracterizando-se como um ambiente de RA. Essa visão é obtida por meio da tela do dispositivo móvel enquanto o aplicativo está ativo.

O objeto 1 é um vídeo que apresenta a cena aludida no texto de forma que, ao executar o vídeo, o aluno pode assistir o que foi descrito. Apesar do material fornecer as medidas do fragmento de madeira seria possível, comparando as dimensões dos atores e, por meio de escalas, estimar as dimensões da madeira.

Além dos botões padrões de links do LAYAR (como os objetos 5, 6 e 7) nos quais se pode escolher apenas uma cor e um título para cada botão, também é possível vincular uma imagem prévia. Isso ocorre no objeto 2 , no qual uma imagem do Titanic com a inscrição "para saber mais sobre o Titanic, clique aqui" é observada. Ao clicar no botão o usuário é direcionado para a página do Titanic na wikipedia (WIKIPEDIA, 2016), podendo obter informações sobre o naufrágio mais famoso do mundo.

O objeto 3 é um carrossel de imagens. Neste objeto são exibidas imagens da construção da embarcação, do navio ao desatracar do cais de Southampton e de seus destroços no fundo do mar, além de informações sobre o naufrágio, fotos originais do iceberg envolvido no acidente e a capa do primeiro jornal a anunciar a tragédia.

O objeto 4 é uma imagem individual que compara diversos aspectos do Titanic com o maior transatlântico da atualidade.

O objeto 5 é um botão de link. Ao clicar o usuário é direcionado para uma simulação do PhET sobre flutuabilidade (PHET, 2016). Nela, o estudante pode interagir com objetos que são imersos em líquidos de densidades diferentes, investigar as grandezas físicas das quais o empuxo depende e as condições necessárias para um objeto boiar em um fluido. Ademais, por fornecer valores numéricos, pode-se discutir conceitos como peso aparente, forças peso e empuxo de forma quantitativa. Essa simulação pode ser empregada como uma forma de retomar alguns conceitos já discutidos em aula e auxiliar na resolução do problema proposto.

O objeto 6 também é um botão de link. Clicando-o, o aluno é direcionado ao artigo de Martins (2000). Nele o autor explora o método mais difundido nos livros didáticos pelo qual Arquimedes teria descoberto a falsidade da coroa do rei Hieron de Siracusa. Discute a possível origem da história, aponta aspectos que mostram que este procedimento é implausível e menciona um texto de Galileo que analisa um método que possivelmente tenha sido utilizado por Arquimedes, caso a história seja de fato verdadeira. Este é um bom exemplo de como trabalhar de uma maneira mais desejável a História e a Natureza da Ciência em sala de aula.

O objeto 7 é um botão de link que direciona para o artigo de Oliveira (2012) e apresenta o problema proposto no material. Além de conter a resolução da situação, discute outros casos que podem ser explorados a partir da problematização inicial. Além disso, é um bom exemplo de como se pode trabalhar um problema matemático por um viés que instigue a curiosidade dos estudantes e seja significativa para eles.

Podemos observar que o software permite incorporar ao texto impresso sons, imagens, vídeos, simulações e materiais complementares, ampliando as possibilidades de interação e o acesso à informação por parte do usuário. $\mathrm{O}$ material foi utilizado em um minicurso de formação de professores, contudo, pensamos que seu uso com alunos de ensino médio exigiria algumas adequações, sobretudo no que diz respeito aos objetos $6 \mathrm{e}$ 7. Também seria interessante que alguns outros elementos de RA fossem incorporados a fim de contribuir para a resolução da atividade por parte dos discentes. A partir da situação virtual poderia ser sugerido que os alunos realizassem uma atividade de investigação, elaborando um experimento real que pudesse verificar o problema proposto. Esse experimento poderia ser registrado em vídeo e socializado em uma página específica do facebook previamente definida e direcionada por um objeto de RA. 


\section{Considerações Finais}

Neste trabalho apresentamos o software de RA LAYAR como um suporte para aulas de física e acreditamos que muitos dos recursos disponíveis estão em concordância com o preconizado em estudos acerca das novas diretrizes de ensino. Por permitir a sobreposição de diversos elementos virtuais sobre um material impresso, ele atende a uma das demandas dos nativos digitais: o acesso rápido e simultâneo a variadas fontes de informação e consulta. Viabiliza o uso de textos impressos (uma característica dos professores imigrantes digitais) em concomitância com a disponibilidade de vídeos, sons, imagens e links que são uma preferência dos nativos digitais. Os diferentes recursos são apresentados conjuntamente, de forma que o aluno não necessita seguir uma ordem préestabelecida, mas pode interagir como desejar, de forma livre, aleatória e no seu ritmo. $\mathrm{O}$ LAYAR é um recurso moderno e dinâmico que atende as características da geração digital fato que possivelmente atraia o interesse dos alunos, motivando-os a aprenderem mais. Por estarem constantemente conectados e utilizando smartphones é possível que isso facilite o uso do aplicativo para fins acadêmicos mesmo fora do ambiente escolar.

O uso da RA pode ser estendido para outras disciplinas, bem como se mostra uma interessante e versátil ferramenta para o desenvolvimento de projetos inter $\mathrm{e}$ transdisciplinares. Acreditamos que a partir da criatividade do professor em desenvolver materiais com recursos de RA o descompasso entre os nativos e os imigrantes digitais possa ser diminuído favorecendo o estabelecimento de um ambiente que potencialize a construção do conhecimento.

Por fim, uma pesquisa em andamento e conduzida pelos autores está avaliando o uso de elementos de RA inseridos via LAYAR em materiais didáticos de alunos de ensino médio. Resultados preliminares indicam que os alunos fazem uso do aplicativo fora do ambiente escolar e acreditam que os elementos de RA contribuem para a compreensão dos conceitos estudados em aula. Nos próximos meses faremos uma avaliação extensa contemplando diferentes perspectivas e tornaremos público os resultados encontrados, complementando o trabalho aqui apresentado.

\section{Referências}

ANDRADE, R. R. D.; NASCIMENTO, R. S.; GERMANO, M. G.. Influências da Física moderna na obra de Salvador Dalí. Caderno Brasileiro de Ensino de Física, v. 24, n. 3, p. 400-423, 2008.

AZUMA, R. T.. A survey of augmented reality. Presence, v. 6, n. 4, p. 355-385, 1997.

CAMARGO, C. X.; CAMARGO, V. A. X.; RAIMANN, E.; CUNHA, I.T.; RIBEIRO, M.W.S.. Aplicações de Realidade Aumentada para Ensino de Física no Instituto Federal de Educação, Ciência e Tecnologia de Goiás - Campus Jataí. Atas do VII workshop de realidade virtual e aumentada. São Paulo, 2010.

CARDOSO, R. G. S.; PEREIRA, S. T.; CRUZ, J. H.; ALMEIDA, W. R. M.. Uso da realidade aumentada em auxílio à Educação. Anais do Computer on the Beach 2014. Florianópolis, 2014.

FORTE, C. E.; KIRNER, C.. Usando Realidade Aumentada no Desenvolvimento de Ferramenta para Aprendizagem de Física e Matemática. Atas do $6^{\circ}$ Workshop de realidade virtual e aumentada. Santos, 2009.

GARCÍA, F.; PORTILLO, J.; ROMO, J.; BENITO, M.. Nativos digitales y modelos de aprendizaje. Anais do IV Simposio pluridisciplinar sobre diseño, evaluación y desarrollo de contenidos educativos reutilizables, Bilbao, 2007. 
GOMES, T. C.; DI GIORGI, C. A. G.; RABONI,P. C. A. Física e pintura: dimensões de uma relação e suas potencialidades no ensino de física. Revista Brasileira de Ensino de Física, v. 33, n. 4, p. 4402, 2011.

KIRNER, C.; KIRNER, T. G.. Virtual Reality and Augmented Reality Applied to Simulation Visualization. In: El Sheikh, A.A.R.; Al Ajeeli, A.; Abu Taieh, E.M.O.. (Org.). Simulation and Modeling: Current Technologies and Applications. 1 ed. Hershey-NY: IGI Publishing, 2007, v. 1, p. 391-419.

LABURÚ, C. E.; ARRUDA, S. M.; NARDI, R. Pluralismo metodológico no ensino de ciências Ciência \& Educação, v. 9, n. 2, p. 247-260, 2003.

MARTINS, R. A.. Arquimedes e a coroa do rei: problemas históricos. Caderno Brasileiro de Ensino de Física, v. 17, n. 2, p. 115-121, 2000.

MOREIRA, I. C.; MASSARANI, L. (En)canto científico: temas de ciência em letras da música popular brasileira. Historia, ciências, saúde, v. 13, p. 291-307, 2006.

OLIVEIRA, L. D. Aprendendo Física com o Homem Aranha: Utilizando cenas do filme para discutir conceitos de Física no Ensino Médio. Física na Escola, v. 7, n. 2, p. 79-83, 2006.

OLIVEIRA, L. D.. Titanic, Jack, Rose e o Princípio de Arquimedes. Caderno Brasileiro de Ensino de Física, v. 29, n. 2, p. 283-288, 2012.

PHET INTERACTIVE SIMULATIONS. Disponível em: < https://phet.colorado.edu/sims/density-and-buoyancy/buoyancy_pt_BR.html>. Acesso em: 5 jan. 2016.

PIASSI, L. P. C.. Clássicos do cinema nas aulas de ciências- A física em 2001: uma odisseia no espaço. Ciencia \& Educação, v. 19, n. 3, p. 517-534, 2013.

PRENSKY, M. Digital natives, digital immigrants part 1. On the horizon, v. 9, n. 5, p. $1-6,2001$.

ROLIM, A. L. S.; RODRIGUES, R. L.; OLIVEIRA, W.; FARIAS, D. S.. Realidade aumentada no ensino de ciências: tecnologia auxiliando a visualização da informação. Atas do VIII encontro nacional de pesquisa em educação em ciências. Campinas, 2011.

SILVEIRA, F. L.. Um interessante e educativo problema de cinemática elementar aplicada ao trânsito de veículos automotores-a diferença entre $60 \mathrm{~km} / \mathrm{h}$ e 65 km/h. Caderno Brasileiro de Ensino de Física, v. 28, n. 2, p. 468-475, 2011.

SOUSA, M. C. J. O uso da realidade aumentada no ensino de física. 2015. $134 f$. Dissertação (Mestrado). Faculdade de educação, Instituto de Física, Instituto de Química e Instituto de Biociências, Universidade de São Paulo, 2015.

SOUZA, R. C.; KIRNER, C.. Ensino e Aprendizagem de Eletromagnetismo usando Recursos de Realidade Aumentada. RENOTE, v. 9, n. 1, 2011.

SOUZA, W.; MOREIRA, L. F. 007-Permissão para Educar: Uma Aplicação de Recursos de Mídia no Ensino da Física. Atas do XVI Simpósio Nacional de ensino de Física. SBF, Rio de Janeiro, 2005.

VIEGAS, M. A. C.; VIEIRA, M. B.; SILVA, R. L. S.. Ferramenta de Apoio ao ensino de Física utilizando Realidade Aumentada. Revista Brasileira de Informática na Educação, v. 20, n. 2, p. 60-73, 2012.

WIKIPEDIA.COM. Disponível em: <https://pt.wikipedia.org/wiki/RMS_Titanic>. Acesso em: 5 jan. 2016. 